\title{
O IMPACTO DA POLÍTICA PÚBLICA DO SIMPLES NACIONAL SOBRE A ARRECADAÇÃO DO ICMS \\ Daniel Rodrigues Cordeiro ${ }^{1}$ Everlam Elias Montibeler ${ }^{2}$ Daniel Ribeiro de Oliveira ${ }^{3}$
}

Resumo: Este estudo procurou estimar o impacto da política pública do Simples Nacional sobre a arrecadação de ICMS, e para isso, utilizou-se o método econométrico de dados em painel: ferramenta sofisticada para análise de dados compostos por séries de tempo e corte transversal. As estimativas apontaram que para cada trabalhador contratado por uma empresa que optou pelo regime tributário do Simples Nacional, se produziu um aumento médio anual na arrecadação de ICMS da ordem de $\mathrm{R} \$ 268,09$, e para cada nova empresa optante do Simples Nacional, se incrementou a arrecadação de ICMS a uma média anual de $R \$ 251,53$. Assim, os resultados apontaram que a política pública do Simples Nacional foi eficaz no seu objetivo de aumentar a arrecadação tributária.

Palavras-chave: Políticas Públicas. Avaliação de Políticas. Simples Nacional.

\section{THE IMPACT OF THE PUBLIC POLICY OF THE SIMPLE NATIONAL ON THE COLLECTION OF ICMS}

Abstract: This study aimed to estimate the impact of Simples Nacional's public policy on ICMS collection. For this purpose, the econometric method of panel data was used: a sophisticated tool for data analysis composed of time series and crosssectional data. Estimates indicated that for each worker hired by a company that opted for the Simple National regime, an average annual increase in ICMS tax collection of around $\mathrm{R} \$ 268.09$ was produced, and for each new company that opted for the Simple National tax system, the tax revenue increased of ICMS at an annual average of $R \$ 251.53$. Thus, the results indicated that Simples Nacional's public policy was effective in its objective of increasing tax collection.

Keywords: Public Policies. Policies Evaluation. Simples Nacional.

\section{EL IMPACTO DE LA POLÍTICA PÚBLICA DEL SIMPLE NACIONAL SOBRE LA ARRECADA DEL ICMS}

Resumen: El objetivo de este estudio fue estimar el impacto de la política pública de Simples Nacional en la recaudación de ICMS. Para este propósito, se utilizó el método econométrico de datos de panel: una herramienta sofisticada para el análisis de datos compuestos por series de tiempo y datos transversales. Las estimaciones indicaron que por cada trabajador contratado por una empresa que optó por el régimen Simples Nacional se produjo un aumento anual, promedio, en la recaudación de ICMS de alrededor de $R \$ 268,09$; y que por cada nueva empresa que optó por el sistema fiscal Simples Nacional, los ingresos fiscales de ICMS aumentaron un promedio anual de $\mathrm{R} \$ 251,53$. Por lo tanto, los resultados indican que la política pública de Simples Nacional fue eficaz en su objetivo de aumento de la recaudación de impuestos.

Palabras clave: Políticas públicas. Evaluación de Políticas. Simples Nacional.

\footnotetext{
1Universidade Iguaçu, Departamento de Administração, Nova Iguaçu, Brasil, danielrodriguesco@gmail.com, https://orcid.org/0000-0002-3127-7083

2Universidade Federal Rural do Rio de Janeiro, Departamento de Economia, Seropédica, Brasil, everlamelias@gmail.com, https://orcid.org/0000-0001-8899-8669

3Universidade Federal Rural do Rio de Janeiro, Departamento de Economia, Seropédica, Brasil, daniel.eco@uol.com.br, https://orcid.org/0000-0002-8787-8320
} 


\section{Introdução}

Alguns autores introduziram a ideia de que a política pública seria como um ciclo formado por diversas etapas que constituiriam um processo de aprendizado e dinâmico ao mesmo tempo. Estas etapas do ciclo político (policy cycle) são separadas entre: (i) definição da agenda; (ii) formulação de políticas; (iii) tomada de decisão; (iv) implementação de políticas; e (v) avaliação de políticas. Estas etapas podem ser enquadradas em três grandes fases: (a) definição de agenda (fase política); (b) formulação de políticas e a tomada de decisão (fases técnicas); e (c) implementação e avaliação de políticas são fases organizacionais (SOUZA, 2006; WU et al., 2014).

Conforme apresentada as etapas do ciclo de políticas públicas, este trabalho buscou focar na quinta etapa: avaliação de políticas; em especial, avaliar a política pública voltada às Micro e Pequenas Empresas (MPEs), que ficou mais conhecida como a política pública do "Simples Nacional", que se consolidou através da Lei Complementar no 123 de 14 de dezembro de 2006 - LC 123/2006 (BRASIL, 2006), cujo objetivo era o de criar um regime de tributação simplificado e diferenciado para estas empresas, facilitando assim, alguns processos como o de: (a) formalização destas empresas; (b) envio de obrigações informativas para os fiscos dos entes federativos; (c) recolhimento dos tributos centralizados em uma única guia de arrecadação; (d) redução da carga tributária sobre o faturamento; (e) redução dos encargos trabalhistas e sociais sobre a folha de pagamento, assim como outros processos que buscavam ser menos complexos para estas empresas. E acreditavase que com isso, também se fomentaria a geração de novas vagas de empregos e do aumento de arrecadação tributária, que são alguns dos objetivos do Simples Nacional.

A história do Regime Especial Unificado de Arrecadação de Tributos e Contribuições Devidos pelas Microempresas e Empresas de Pequeno Porte (SIMPLES NACIONAL), retorna aos anos 70, quando foi realizado o primeiro Congresso Brasileiro das Micro e Pequenas Empresas. E na década seguinte, pôdese perceber uma grande vitória, ainda que simbólica, com a inclusão dos artigos 170 e 179 da Constituição Federal de 1988 (CF/88), onde se destacava a obrigação de conceder tratamento diferenciado e favorecido às microempresas e às empresas de pequeno porte e de simplificar suas obrigações creditícias, previdenciárias, administrativas e tributárias (SENADO FEDERAL, 2017). 
Sendo assim, a primeira ação de valorização da importância das MPEs no Brasil só se deu a partir da CF/88. O Brasil encontrava-se 30 anos atrasado em relação às principais economias do mundo, que desde a década de 50 já destinavam tratamento diferenciado à estas empresas, às quais eram, e são até o momento, as empresas que mais geram empregos (PORTAL LEI GERAL DA MICRO E PEQUENA EMPRESA, 2015). De acordo com o estudo feito pelo Serviço Brasileiro de Apoio às Micro e Pequenas Empresas (SEBRAE, 2017a), que ficou conhecido como Anuário do Trabalho nos Pequenos Negócios, em sua oitava edição que se refere ao ano de 2015, informa que entre 2005 e 2015 o número de MPEs cresceu $27,5 \%$ e o de empregos formais gerado por elas da ordem de 55,3\%. Em 2015, as MPEs responderam, em média, por 99\% dos estabelecimentos do país, representando $54 \%$ dos empregos formais de estabelecimentos privados não agrícolas do país e quase $44 \%$ da massa de salários paga aos trabalhadores destes estabelecimentos.

Desta forma, o presente artigo ficou estruturado em quatro grandes partes, além desta introdução: (i) referencial teórico: buscou trazer a discussão sobre avaliação de políticas públicas e sobre a política pública do Simples Nacional e as hipóteses do trabalho; (ii) metodologia: buscou descrever o método da regressão linear múltipla e explicar as variáveis utilizadas neste artigo; (iii) análise dos resultados: buscou dividir a discussão entre a análise dos resultados estaduais e dos resultados regionais; e por fim, (iv) considerações finais: buscou trazer o debate sobre os resultados discutidos neste artigo.

\section{Avaliação de Políticas Públicas}

A existência de diferentes formas de classificação da avaliação é enfatizada pelo fato de não existir uma única definição sobre isto. Ala-Harja e Helgason (2000), destacam que a inexistência de uma definição única sobre avaliação de políticas públicas se explica pelo fato de a área de políticas públicas ser perpassada por uma variedade de disciplinas, instituições e executores, abrangendo diversas questões, necessidades e pessoas.

A avaliação pode ser classificada em função do seu timing, ou seja, se ela é feita antes, durante ou depois da implementação da política pública. Nesse sentido, a avaliação não ocorre apenas no final do ciclo da política pública, como apregoado pelo modelo do ciclo. Contudo, ele é apenas uma forma de analisar as políticas públicas, dividindo-as em etapas, pois, na realidade elas não necessariamente 
seguem aqueles passos de forma linear e dificilmente são feitas seguindo a estrutura imaginada (FARIA, 2005; RAMOS e SCHABBACH, 2012).

Quanto as classificações da avaliação em função do seu timing, a primeira pode ser considerada como a realizada antes da implementação (ex-ante), ocorre logo no início do programa; o objetivo é o de auxiliar na decisão de implementar ou não uma política pública. Outra classificação possível é a intermediária (in-itineri), esta ocorre durante a implementação da política, geralmente é adotada como um meio de adquirir conhecimento; o objetivo é o de dar suporte e melhorar a gestão, a implementação e o desenvolvimento do programa. $E$ também tem a que é realizada depois da implementação (ex-post), o objetivo é o de avaliar a sua eficácia e o julgamento de seu valor de uma forma geral (COHEN e FRANCO, 1999; ALAHARJA e HELGASON, 2000). Em vista disso, a avaliação de políticas públicas possibilita que os formuladores e os implementadores das políticas sejam capazes de tomar decisões com maior assertividade, e assim, maximizar os gastos públicos nas diversas atividades onde se tem influência estatal (FERREIRA, ALENCAR e PEREIRA 2012).

Notando estas possíveis interpretações e momentos em que a avaliação de uma política pública pode ser feita, para este artigo, a avaliação da política pública do Simples Nacional foi classificada em função do seu timing, como ex-post, uma vez que buscou-se avaliar a política depois da sua implementação, com propósito de avaliar o impacto em relação a alguns de seus objetivos, como o de arrecadação de ICMS para os estados e o da geração de empregos.

Como o relatório mais recente sobre a avaliação do Simples Nacional, foi o "Relatório de avaliação da política pública do Simples Nacional - regime especial unificado de arrecadação de tributos e contribuições devidos pelas microempresas e empresas de pequeno porte - em atendimento ao que dispõe a resolução do Senado Federal no 44, de 2013 e ao requerimento n 16/2017", realizado pela Comissão de Assuntos Econômicos (CAE) do Senado Federal (2017), não contém números específicos em relação as metas de geração de emprego e/ou de arrecadação, para este artigo, utilizou-se o termo "avaliação de impacto", que para Figueiredo e Figueiredo (1986), diz respeito aos efeitos de um programa implementado sobre um público-alvo, e que tem a intenção de estabelecer uma relação de causalidade entre a política pública implementada e as suas alterações causadas nas condições sociais deste público. Desta forma, a avaliação da política pública do Simples 
Nacional foi realizada em função dos impactos destes dois objetivos destacados anteriormente.

\section{Simples Nacional}

A proposta para a criação da Lei Complementar no 123 de 14 de dezembro de 2006, também conhecida como a Lei Geral das Micro e Pequenas Empresas, foi concretizada pelo Serviço Brasileiro de Apoio às Micro e Pequenas Empresas (SEBRAE), que buscava atender as reivindicações constantes do segmento. A ideia da proposta surgiu em outubro de 2003, nas comemorações da "Semana da Micro e Pequena Empresa", onde foram discutidas e apontadas as principais necessidades do segmento, e estes debates foram realizados através de seminários que contavam com a presença de empresários em todos os estados. Foi neste momento em que se teve início à ideia da Lei Geral, que três anos depois viria a ser sancionada pela Presidência da República, através da LC 123/2006 (TAVARES, 2007).

Ainda de acordo com Tavares (2007), em abril de 2005, houve uma retomada no debate a respeito da proposta de criação da lei que viria beneficiar os micro e pequenos empresários, e foi a partir deste momento que ocorreu o surgimento da "Frente Empresarial pela Lei Geral", que era integrada pelas Confederações Nacionais: da Indústria ( $\mathrm{CNI}$ ), do Comércio $(\mathrm{CNC})$, da Agricultura (CNA), dos Transportes (CNT), de Dirigentes Lojistas (CNDL), das Associações Comerciais e Empresariais do Brasil (CACB), entre outras, contando também com o apoio do SEBRAE. Contudo, a proposta só começou a tramitar oficialmente na Câmara dos Deputados em 16 de novembro de 2005, e após intensas e longas negociações (entre deputados e governo), foi aprovada em 05 setembro de 2006. Já no Senado Federal ocorreram mais negociações até a aprovação do texto, que ocorreu em 08 novembro de 2006. Porém, com modificações introduzidas pelos senadores, a proposta voltou para a Câmara dos Deputados, onde ocorreram novas negociações até a sua finalização, em 22 de novembro de 2006. Com isso, notou-se uma extensa discussão a respeito da proposta, não somente durante os três anos anteriores à criação da lei, mas também no momento de sua tramitação oficial no Congresso Nacional.

De acordo com a Receita Federal do Brasil (RFB 2018, p. 14), "o Simples Nacional é uma abreviação do Regime Especial Unificado de Arrecadação de Tributos e Contribuições devidos pelas Microempresas e Empresas de Pequeno Porte". O objetivo é fomentar o desenvolvimento e a competitividade das micro e 
pequenas empresas, como estratégia de geração de emprego, distribuição de renda e fortalecimento da economia.

Desta maneira, o Simples Nacional pode ser entendido como o regime tributário diferenciado, simplificado e favorecido, criado através da LC 123/2006, que está em vigor desde julho de 2007, e que buscou simplificar e reduzir o peso dos tributos sobre os Pequenos Negócios no Brasil. Foi precedido na década anterior à sua criação pelo Simples Federal, versão que abrangia apenas impostos federais (SEBRAE, 2017b).

Uma das principais críticas ao Simples Nacional era que muitas atividades eram impedidas de aderi-lo, em especial as empresas de serviços, que representam o setor com maior potencial de criação de novas empresas. Com isso, entre os anos de 2007 e 2009, ocorreram sucessivas extensões do Simples Nacional para novas atividades, em especial, às empresas do setor de serviços (SEBRAE, 2016; 2017b).

Um dado importante de se destacar é o do SEBRAE (2017b), em relação a forte expansão do número de optantes do Simples Nacional (puxado pelo MEI), e o grau de informalidade dos Pequenos Negócios. De acordo com eles, em 2007 o número de empreendimentos optantes pelo Simples Nacional representavam apenas $11 \%$ dos Donos de Negócios (esse baixo percentual pode ser explicado pelo fato de 2007 ter sido o ano em que a política pública do Simples Nacional entrou em vigor ou pela restrição de atividades de quem poderia adotar esta política), mas, que em 2016 este percentual subiu para 45\% e que até o final de 2017, o grau de formalização dos Pequenos Negócios deveria chegar a 50\%. Desta maneira, com base nesta projeção para 2017, pôde se afirmar que esta política pública ajudou na formalização de $50 \%$ dos Pequenos Negócios, assim, atingindo um de seus objetivos.

Importante destacar que a figura do MEI só passou a entrar em vigor em julho de 2009, sendo assim, no início da política pública do Simples Nacional, havia cerca de 2,5 milhões de pequenos negócios formalizados, e até outubro de 2017 este número subiu para aproximadamente 12,5 milhões (SENADO FEDERAL, 2017).

Desta maneira, o presente artigo partiu das hipóteses de que a política pública do Simples Nacional teve resultados positivos na arrecadação do ICMS e que a geração de empregos foi a que mais impactou no aumento da arrecadação. Como destacado por Gabriel (2014, p. 354), "as pesquisas com delineamento quantitativo pressupõem a definição do papel de cada variável e a relação entre elas, gerando hipóteses a serem testadas durante a análise dos dados coletados". 
Já para Marconi e Lakatos (2003), a hipótese de um trabalho é uma suposta, provável e provisória resposta a um problema, cuja comprovação será verificada através da pesquisa, e que apresentam algumas outras características como o fato de ser passível de verificação empírica em suas consequências. Desta forma, as variáveis foram descritas na parte da metodologia e as hipóteses deste artigo, foram:

$\checkmark \quad \mathrm{H}_{1}$ : A política pública do Simples Nacional causou impacto positivo na arrecadação do ICMS; e

$\checkmark \quad \mathrm{H}_{2}$ : O emprego impactou positivamente no aumento da arrecadação do ICMS.

\section{Regressão Linear Múltipla}

De acordo com Gujarati (2003), o entendimento moderno sobre a regressão é bastante diferente das ideias iniciais. Em termos gerais, pode-se dizer que a análise de regressão está preocupada com o estudo da dependência de uma variável (variável dependente ou explicada), em uma ou mais outras variáveis (variáveis independentes ou explicativas), cujo objetivo é o de estimar e/ou prever algo. Diferentemente das regressões de séries temporais ou de dados transversais, os modelos de dados em painel têm duas subclassificações, as de tempo e indivíduos:

$$
Y_{i, t}=\beta_{0}+\beta_{1} x_{1 i, t}+\beta_{2} x_{2 i, t}+\cdots+\beta_{n} x_{n i, t}+\varepsilon_{i, t}
$$

Onde: $Y_{i t}$ é a variável dependente; $x_{i t}$ variáveis independentes existentes de $i$ indivíduos, representando os dados de corte transversal em que $i \in(1,2,3, \ldots, N)$ e $t$ o número de períodos, indicando a série de tempo, em que $t \in(1,2,3, \ldots, N) ; \beta_{0}, \beta_{1}$, $\beta_{2}$ e $\beta_{n}$ são os parâmetros da regressão; e $\varepsilon_{i t}$ é o termo que representa o resíduo ou erro da regressão.

Os coeficientes ou parâmetros da regressão $\beta_{0}, \beta_{1}, \beta_{2}$ e $\beta_{n}$ são descritos por Montgomery, Peck e Vining (2012), como: $\beta_{0}$ sendo o coeficiente intercepto ou linear, o qual corresponde à média de $Y$ quando todas as variáveis de controle são iguais a zero, ou seja, ele representa o valor de $Y$ quando $X$ é igual a zero; os coeficientes $\beta_{1}, \beta_{2}$ e $\beta_{n}$ como coeficientes de regressão parcial ou angular.

Para este artigo, $i$ indica os estados brasileiros e as regiões do país (modelo I e II), respectivamente, $\beta_{0}$ é o intercepto que é representado por uma variável escalar e que é fixa no tempo (valor previsível, não aleatório), $\beta_{1}, \beta_{2} e \beta_{n}$ os coeficientes 
angulares (ou parâmetros) que serão testados e $x_{1 i t}$ é a variável Optantes pelo Simples Nacional (que foi utilizada nos dois modelos); $x_{2 i t}$ é a variável Emprego (que também foi utilizada nos dois modelos); que variam em função do tempo $t$ dos anos estudados e em cada estado e regiões $i$. Já $Y_{i t}$ é a variável dependente que mede a arrecadação de ICMS do Simples Nacional dos estados e regiões e $\varepsilon_{i t}$ é o valor não observável do efeito individual especificado, ou seja, a variável de erro/distúrbio que faz com que os impactos dos Optantes pelo Simples Nacional e do Emprego sobre a arrecadação não alcancem os valores esperados.

Sendo assim, o presente artigo buscou, através da análise da regressão linear múltipla, utilizar as variáveis independentes: a) OPSN = Optantes pelo Simples Nacional; e b) EMPREGO = Empregos. E a variável dependente foi: a) ICMSSN = ICMS Simples Nacional (utilizado no primeiro e segundo modelo). O período abrangido foi de 2010 a 2016.

Após as definições das variáveis utilizadas, pôde-se descrever as equações matemáticas que foram utilizadas neste artigo para os dois modelos (modelo $\mathrm{I}=$ análise estadual e modelo $\mathrm{II}$ = análise regional):

$$
\text { ICMSSN }_{\mathrm{i}, \mathrm{t}}=\beta_{0}+\beta_{1} \text { OPSN }_{1 \mathrm{i}, \mathrm{t}}+\beta_{2} \text { EMPREGO }_{2 \mathrm{i}, \mathrm{t}}+\varepsilon_{\mathrm{i}, \mathrm{t}}
$$

A regressão com dados em painel, ou dados longitudinais, é uma ferramenta poderosa na análise de dados que utiliza tanto séries temporais quanto seção cruzada ou corte transversal. Os dados em painel possibilitam estimar os efeitos das variáveis não observadas entre os distintos grupos, revelando a heterogeneidade individual. Outra vantagem é possibilidade de se trabalhar com uma base de dados ampliada e com maior grau de liberdade, o que coopera para a eficiência dos resultados (ARELLANO, 2004).

Retomando o ponto sobre os dados em painel, para Hsiao (2014) uma das principais vantagens da análise de dados em painel é a utilização de um maior número de informações, a redução dos problemas de colinearidade e o aumento da eficiência na estimação. A união de séries temporais e cross section aumenta o grau de liberdade da amostra, ou seja, aumenta o número de observações em relação ao número de parâmetros que se busca estimar. Quanto maior o tamanho da amostra, maior o grau de liberdade e, consequentemente, melhor será o resultado da nossa estimação dos valores dos parâmetros. 


\section{Análise Estadual}

Esta primeira análise buscou verificar os impactos das variáveis Emprego e Optantes pelo Simples Nacional (variáveis independentes), sobre a arrecadação do ICMS do Simples Nacional (variável dependente), no período de 2010 a 2016, contando com os 27 indivíduos da equação (neste caso, os estados do país). E antes de se iniciar a realização dos testes dos pressupostos, foi rodada a regressão contendo todos os indivíduos e tempos de todas as variáveis em um único modelo, e notou-se que o modelo não atendia dois pressupostos: o da homoscedasticidade e o da ausência de auto correlação, sendo assim, optou-se por aplicar a defasagem na variável dependente para correção deste último pressuposto, buscando assim aumentar a eficiência do método.

Antes de iniciar os testes dos pressupostos, se fez necessário a verificação de qual modelo de regressão seria utilizado (fixo ou aleatório) e depois o da confirmação, se dentre um destes dois e o modelo pooled, qual seria o mais adequado para a análise dos estados. Sendo assim, iniciou-se com o teste de Hausman (anexo I), para verificação de qual dos modelos, entre os modelos fixo e aleatório, seria o mais adequado. $O$ resultado indicou que o modelo mais adequado a ser utilizado, neste caso, foi o dos efeitos fixos. Posteriormente foi realizado o teste de Chow (resultado encontra-se abaixo na tabela de saídas da regressão; tabela 01), para verificar se entre o modelo pooled e o do efeito fixo, qual seria o mais apropriado, e o resultado apresentado foi o de que o modelo dos efeitos fixos seria 0 melhor para este caso.

Após testar os pressupostos do modelo de regressão utilizado para o modelo I, foi rodada a regressão através do modelo dos efeitos fixos, onde foram utilizadas 162 observações, incluídas 27 unidades de corte transversal (estados brasileiros), com o comprimento da série temporal de 6 anos (anos estudados menos a defasagem utilizada na variável dependente), e o painel foi considerado balanceado, uma vez que todos os campos da base de dados foram preenchidos.

Tabela 01 - Regressão sobre efeitos fixos (modelo I)

\begin{tabular}{lr}
\hline $\begin{array}{l}\text { Fixed-effects (within) regression } \\
162\end{array}$ & Number of obs $=$ \\
$\begin{array}{l}\text { Group variable: ID } \\
27 \quad \text { within }=0.9413\end{array}$ & Number of groups $=$ \\
$\begin{array}{l}\text { R-sq: between }=0.9948 \\
6.0 \quad \text { overall }=0.9907\end{array}$ & Obs per group: avg $=$ \\
$\quad \max =$
\end{tabular}


6 $\begin{array}{lll}\mathrm{F}(3,132) & =705.22 & \text { Prob }>\mathrm{F}\end{array}$

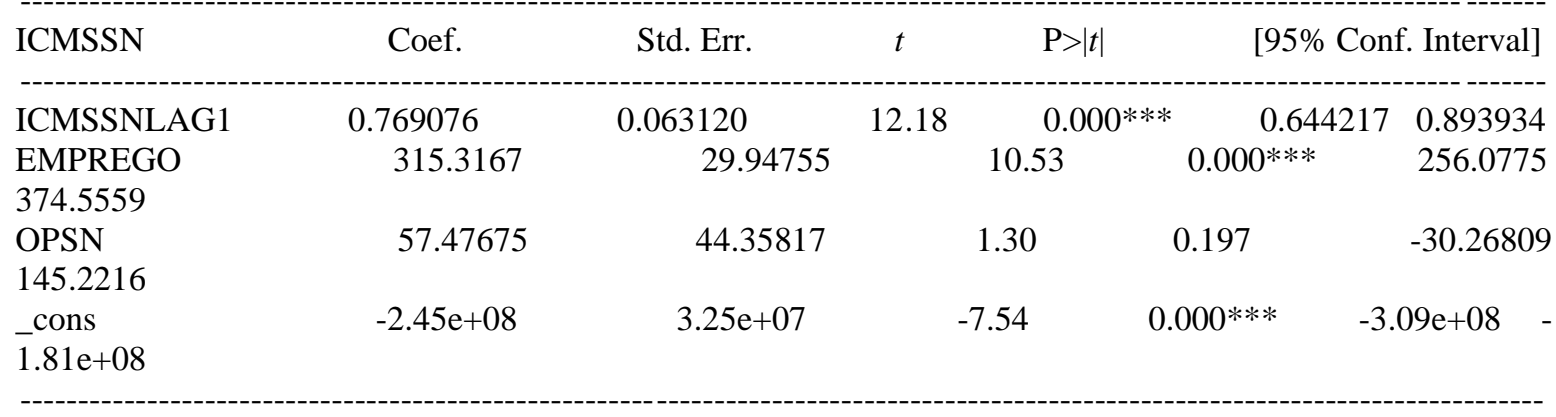

Teste de Chow: $\mathrm{F}(26,132)=4.41$

Prob $>\mathrm{F}=$ 0.0000

Durbin-Watson: $\quad \mathrm{d}_{1} \quad(1,71815) \quad$ e $\quad \mathrm{d}_{\mathrm{u}} \quad(1,7681)$

2,270893

Legenda: ${ }^{*} 90 \%$ de significância; ${ }^{\star *} 95 \%$ de significância; e ${ }^{\star \star \star} 99 \%$ de significância.

Fonte: Dados da pesquisa.

A primeira observação feita foi a da significância estatística das variáveis, sendo assim, das variáveis independentes (ICMSSNLAG1, EMPREGO e OPSN), a única a não obter significância estatística foi a variável OPSN, o que significa dizer que não houve análise a ser feita sobre esta variável, uma vez que ela não apresentou significância estatística. Desta forma, foi possível analisar o impacto das outras duas variáveis independentes sobre a variável dependente (ICMSSN). Outro ponto importante de se analisar no modelo é o valor do $\mathrm{R}^{2}$, também conhecido como coeficiente de determinação, que para este modelo I, foi de 0,9907 , ou seja, significa dizer que as variáveis utilizadas conseguem explicar 99,07\% do modelo utilizado. De acordo com Gujarati (2003), este coeficiente "é uma medida sintética que diz quão bem a reta de regressão da amostra se ajusta aos dados".

Sobre a avaliação da política pública do Simples Nacional, os dados referentes aos estados puderam ser interpretados da seguinte maneira: o valor do coeficiente da variável EMPREGO foi de 315,3167 ou $R \$ 315,32$, o que significa dizer que a cada 1 emprego gerado por uma empresa optante pelo Simples Nacional, ocasionaria em média (no ano) um aumento de $\mathrm{R} \$ 315,32$ na arrecadação dos estados através do ICMS pago por empresas que adotam esta política pública. Esta relação entre emprego e tributo pode ser explicada pelo consumo, uma vez que a pessoa trabalhando tenderia a consumir produtos que sofrem a incidência do ICMS, como por exemplo: produtos vendidos por empresas do ramo do comércio ou da indústria. Já o valor do coeficiente da variável ICMSSNLAG1 (que é a variável dependente com a defasagem de 1 período), foi de 0,769076 ou $R \$ 0,77$, o que 
significa dizer que para cada 1 real de ICMS arrecadado por empresas optantes pelo Simples Nacional no período anterior, impactaria em média (no ano) um aumento $\mathrm{R} \$$ 0,77 na arrecadação do período atual.

Desta forma, pôde-se notar que no modelo I (composto pelos 27 estados do país), durante o período de 2010 a 2016, obteve os seguintes resultados relacionados aos impactos causados pelas variáveis EMPREGO e ICMSSNLAG1, sobre a arrecadação do ICMS das empresas optantes pelo Simples Nacional (variável ICMSSN): a) 1 emprego = aumento médio anual na arrecadação estadual, através do recolhimento do ICMS, de $\mathrm{R} \$ 315,32$; e b) 1 real de ICMS anterior = aumento médio anual na arrecadação estadual atual, através do recolhimento do ICMS, de $R \$ 0,77$.

Isso demonstrou que no modelo I não se pôde fazer a análise dos impactos da quantidade de optantes pelo Simples Nacional sobre o ICMS arrecadado por empresas optantes pelo regime simplificado de tributação, uma vez que a variável independente OPSN, não obteve significância estatística e, que em relação a política pública do Simples Nacional, pôde-se afirmar que ela causou impactos positivos na arrecadação do ICMS (confirmando a hipótese 1), e a geração de empregos destas empresas contribuiu mais para o aumento da arrecadação do ICMS dos estados (confirmando a hipótese 2), sendo assim, foi possível confirmar as duas hipóteses do artigo, se tratando da análise estadual (modelo I).

\section{Análise Regional}

Esta segunda análise buscou verificar os impactos das variáveis Emprego e Optantes pelo Simples Nacional (variáveis independentes), sobre a arrecadação do ICMS do Simples Nacional (variável dependente), no período de 2010 a 2016, contando com os 5 indivíduos da equação (regiões do país). E antes de se iniciar a realização dos testes dos pressupostos, foi rodada a regressão contendo todos os indivíduos e tempos de todas as variáveis em um único modelo, e notou-se que o modelo não atendia dois pressupostos, o da homoscedasticidade e o da ausência de auto correlação, sendo assim, optou-se por aplicar a defasagem na variável dependente para correção deste último, buscando aumentar a eficiência do método.

Assim como foi feito no modelo anterior, antes de iniciar os testes dos pressupostos se fez necessário a verificação de qual modelo de regressão seria utilizado sobre efeitos fixos ou aleatórios e depois confirmar, se dentre um destes modelos e o modelo pooled, qual seria o mais adequado para a análise das regiões, 
e o resultado indicou que o modelo mais adequado a ser utilizado, neste caso, foi o dos efeitos fixos (anexo II).

Após testar os pressupostos do modelo de regressão utilizado para o modelo II, foi rodada a regressão através do modelo sobre os efeitos fixos, onde foram utilizadas 30 observações, incluídas 5 unidades de corte transversal (regiões), com o comprimento da série temporal de 6 anos (anos estudados menos a defasagem utilizada na variável dependente), e o painel foi considerado balanceado.

Tabela 02 - Regressão sobre efeitos fixos (modelo II)

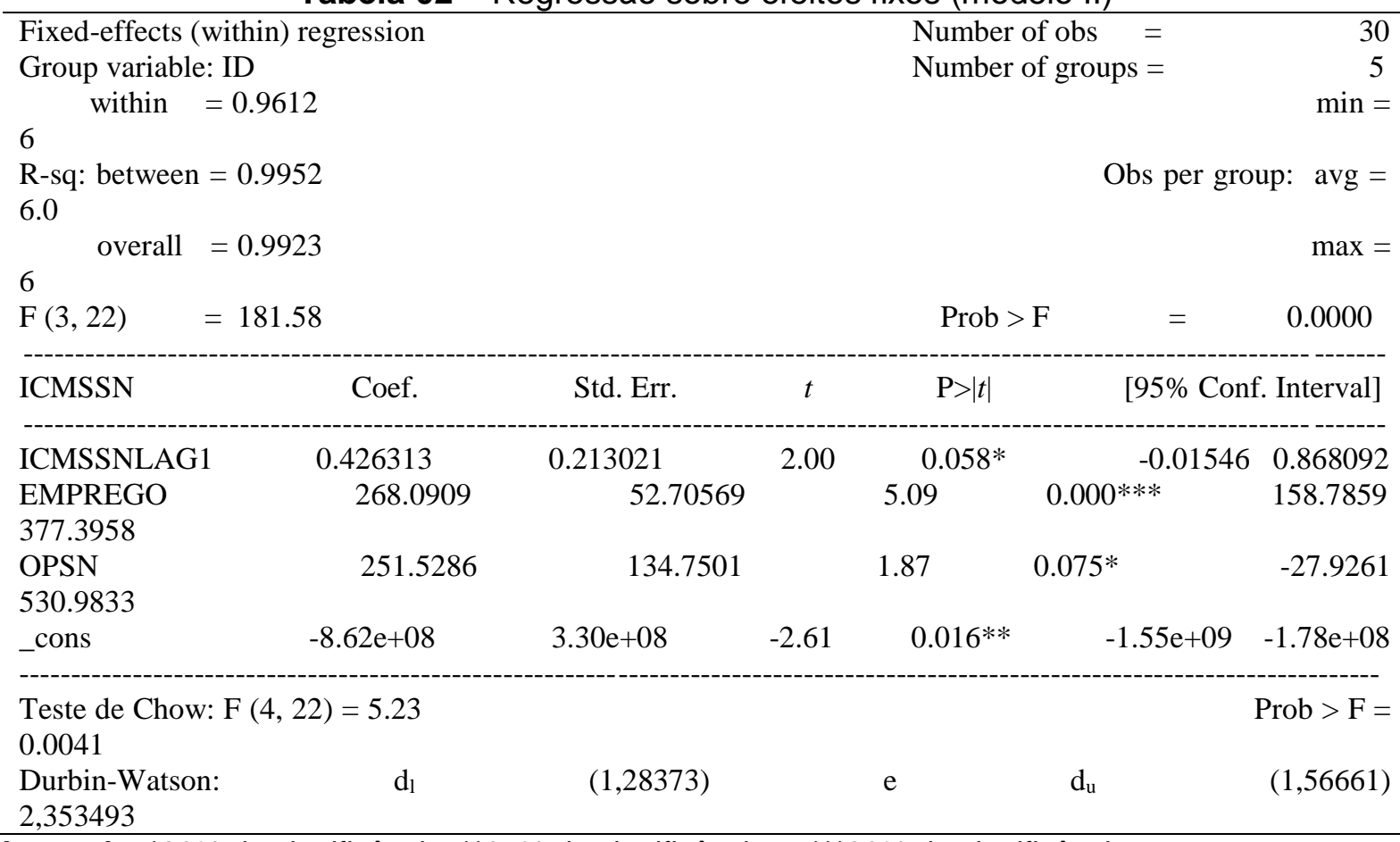

Legenda: *90\% de significância; ** $95 \%$ de significância; e ${ }^{* \star *} 99 \%$ de significância.

Fonte: Dados da pesquisa.

Como já comentado na análise anterior, a primeira observação que se deve ser feita ao analisar o modelo de uma regressão é a da significância estatística das variáveis, sendo assim, das variáveis independentes (ICMSSNLAG1, EMPREGO e OPSN), todas elas obtiveram significância estatística. Desta forma, foi possível analisar o impacto das três variáveis independentes sobre a variável dependente (ICMSSN). Outro ponto importante de se analisar no modelo é o valor do $\mathrm{R}^{2}$, também conhecido como coeficiente de determinação, que para este modelo II foi de 0,9923 , ou seja, significa dizer que as variáveis utilizadas conseguem explicar $99,23 \%$ do modelo utilizado, o que apontou uma pequena melhora no grau de explicação, quando comparada com o modelo anterior, que foi de $99,07 \%$. Essa pequena melhoria no grau de explicação se deu pelo fato de o modelo II poder contar com mais uma variável explicativa, que neste caso, foi a variável OPSN, 
quando comparado com o modelo anterior, ela causou um impacto positivo no grau de explicação de $0,16 \%$.

Os dados referentes as regiões puderam ser interpretados da seguinte maneira: o valor do coeficiente da variável EMPREGO foi de 268,0909 ou $R \$$ 268,09, o que significa dizer que a cada 1 emprego gerado por uma empresa optante pelo Simples Nacional, ocasionaria em média (no ano) um aumento de $R \$$ 268,09 na arrecadação das regiões através do ICMS pago por empresas que adotam esta política pública. E conforme já esclarecido, esta relação entre emprego e tributo pode ser explicada pelo consumo. Notou-se que o valor foi menor do que o obtido no modelo da análise estadual, e a explicação para a redução deste valor se deu pelo fato de a análise anterior não ter considerado a variável OPSN para explicar o modelo, uma vez que a mesma não obteve significância estatística. Desta maneira, no modelo atual, a variável OPSN contribui para explicação do modelo, logo, o valor que antes estava agregado no emprego, passou a ser distribuído entre as outras variáveis explicativas (OPSN e ICMSSNLAG1).

No que se referiu ao valor do coeficiente da variável OPSN, o valor obtido foi de 251,5286 ou $R \$ 251,53$, o que significa dizer que cada 1 optante pelo Simples Nacional, contribuiu em média (no ano) para o aumento de $R$ \$ 251,53 na arrecadação de ICMS regional feito pelas empresas optantes pelo regime tributário simplificado. Esta relação entre empresa e tributo pode ser explicada pela formalização, uma vez que a empresa formalizada passa a ter que emitir notas fiscais para comprovar seu faturamento mensal e sobre este faturamento mensal incidem os tributos (dentre eles está o ICMS). E como esta variável não obteve significância estatística na análise estadual, não se pôde fazer uma comparação como foi feito com a variável emprego.

Por fim, o valor do coeficiente da variável ICMSSNLAG1 (que é a variável dependente com a defasagem de 1 período), foi de 0,426313 ou $R \$ 0,43$, o que significa dizer que para cada 1 real de ICMS arrecadado por empresas optantes pelo Simples Nacional no período anterior, impactou em média (no ano) um aumento $\mathrm{R} \$$ 0,43 na arrecadação do período atual. Nota-se que nesta variável também houve uma redução no valor do coeficiente, e o motivo para isto ter ocorrido pode ser explicado da mesma maneira que foi feito com a variável emprego, que foi devido ao fato deste modelo contar com três variáveis independentes para sua explicação, ou seja, uma variável explicativa a mais que no modelo anterior. 
Com isso, pôde-se notar que no modelo II (composto pelas 5 regiões do país), durante o período de 2010 a 2016, obteve os seguintes resultados relacionados aos impactos causados pelas variáveis EMPREGO, OPSN e ICMSSNLAG1, sobre a arrecadação do ICMS das empresas optantes pelo Simples Nacional (variável ICMSSN): a) 1 emprego = aumento médio anual na arrecadação regional, através do recolhimento do ICMS, de $\mathrm{R} \$ 268,09$; b) 1 optante pelo Simples Nacional = aumento médio anual na arrecadação regional, através do recolhimento do ICMS, de $R \$$ 251,53; e c) 1 real de ICMS anterior = aumento médio anual na arrecadação regional, através do recolhimento do ICMS, de $\mathrm{R} \$ 0,43$.

Isso demonstrou que no modelo II se pôde fazer a análise dos impactos de todas as variáveis explicativas sobre o ICMS arrecadado por empresas optantes pelo regime simplificado de tributação, diferente do que ocorreu na análise anterior, uma vez que a variável independente OPSN, não havia obtido significância estatística. No que diz respeito a política pública do Simples Nacional, pôde-se afirmar que no modelo regional ela também causou impactos positivos, tanto na arrecadação quanto na geração de empregos. Confirmando assim as duas hipóteses do trabalho.

\section{Considerações Finais}

Estes resultados demonstram a importância e a contribuição que pode ocorrer na avaliação de uma política pública, a partir da utilização de um método econométrico, que neste caso foi o da regressão linear múltipla. Os resultados encontrados também servem como indicadores para futuras pesquisas que desejem avaliar a política pública do Simples Nacional sobre a perspectiva de sua eficácia. Lembrando que este tipo de avaliação não pôde ser feita neste artigo, uma vez que o relatório mais recente a respeito desta política pública, que foi o elaborado pelo Senado Federal (2017), não continham números que poderiam ser utilizados como indicadores para mensuração da eficácia da política, motivo pelo qual levou a ser considerado o termo "impacto", ao invés de "eficácia", para este artigo.

Do ponto de vista da administração pública, os resultados encontrados a partir da utilização deste método colaboram para a demonstração de mais uma ferramenta possível de ser utilizada pelos administradores públicos para avaliarem as políticas públicas que estejam sobre seus controles. Com a utilização adequada deste método, os administradores públicos podem ter em mãos números que possam vir a ser utilizados como "guias" para que estes façam a utilização de forma consciente e 
eficiente dos recursos públicos, evitando assim desperdícios e melhorando o funcionamento da máquina pública de uma maneira geral.

Com a otimização da utilização dos recursos públicos de maneira eficiente e eficaz, as políticas públicas podem ser melhoradas a cada etapa de avaliação (que pode ocorrer antes, durante ou depois de sua implementação), e assim, ter seu tempo de existência mais duradouro, o que traz benefícios econômicos e sociais, como é o caso da política pública do Simples Nacional, que dentre os seus objetivos, busca-se a formalização dos indivíduos que trabalham de maneira informal, e como consequência, espera-se a geração cada vez maior de emprego, e consequentemente, a geração de renda.

Quando comparadas as variáveis independentes que mais causaram impactos positivos na variável dependente, que foi a de arrecadação de ICMS do Simples Nacional (ICMSSN), notou-se que a variável emprego foi a que causou o maior impacto positivo na arrecadação, contudo, a variável independente Optantes pelo Simples Nacional (OPSN) também causou impactos positivos, porém, com valores menores. Isso demonstrou que a política pública, de uma maneira geral, contribuiu positivamente para arrecadação de ICMS dos estados brasileiros, tanto via geração de emprego, quanto via formalização de empresas optantes pelo Simples Nacional.

Ainda que os impactos causados por esta política pública tenham sido positivos, no âmbito dos objetivos de geração de emprego e de arrecadação de ICMS, se faz necessário levantar outras discussões possíveis de serem feitas a respeito desta política pública do Simples Nacional, como por exemplo, o fato de que para criação de um regime tributário simplificado, onde ocorrem renúncias fiscais por parte dos governos, deve se avaliar os impactos causados pelo lado que serve de base de sustentação de tais benefícios para as MPEs, ou seja, se os valores das renúncias fiscais são supridos com a geração de empregos e outros objetivos propostos pela por esta política pública.

Outro ponto relevante de ser enfatizado é sobre a acessibilidade de dados a respeito das empresas optantes pelo Simples Nacional, que ficam centralizados somente na base da Receita Federal e com poucas opções de filtros e de variáveis também. E sobre a delimitação deste trabalho, se deu pelo período estudado e sobre as variáveis utilizadas no modelo, que foram somente as que buscaram evidenciar os dois objetivos da política pública do Simples Nacional. 


\section{REFERÊNCIAS}

ALA-HARJA, M.; HELGASON, S. Em direção às melhores práticas de avaliação. Revista do Serviço Público - RSP, v. 51, n. 4, p. 05-60, 2000.

ARELLANO M. Panel Data Econometrics: Advanced Texts in Econometrics, Oxford: University Press, 2004.

BRASIL. Presidência da República. Casa Civil. Lei Complementar no 123 de 14 de dezembro de 2006. Institui o Estatuto Nacional das MPEs. Diário Oficial da União, Brasília, publicado em 15/12/2006; republicado em: 31/01/2009; 31/01/2012 e 6/03/2012.

COHEN, E.; FRANCO, R. Avaliação de projetos sociais. Petrópolis: Vozes, 1999.

FARIA, C. A. P. A política de avaliação de políticas públicas. Revista Brasileira de Ciências Sociais - RBCS, v. 20, n. 59, p. 97-110, 2005.

FERREIRA, P. A.; ALENCAR, E.; PEREIRA, J. R. Revisitando o modelo processual deanálise de políticas públicas a partir das relações entre Estado e sociedade. In: ENCONTRO NACIONALDE PESQUISADORES EM GESTÃO SOCIAL, v. 6., 2012, São Paulo. Trabalhos apresentados...São Paulo: Enapegs, 2012.

FIGUEIREDO, M. F.; FIGUEIREDO, A. M. C. Avaliação política e avaliação de políticas: um quadro de referência teórica. Revista Análise \& Conjuntura, v. 1, n. 3, p. 107-127, 1986.

GABRIEL, M. L. D. Métodos quantitativos em ciências sociais: sugestões para elaboração do relatório de pesquisa. Desenvolvimento em Questão, v. 1, n. 28, 2014.

GUJARATI, D. N. Basic Econometrics, 4ํed. Nova York: McGraw-Hill, 2003.

HSIAO, Ch. Analysis of Panel Data, 3rd edition, Cambridge University Press, 2014.

MARCONI, M. de A.; LAKATOS, E. M. Fundamentos da metodologia científica, 5o ed. São Paulo: Atlas, 2003.

MONTGOMERY, D. C.; PECK, E. A.; VINING, G. G. Introduction to linear regression analysis, 5으. New Jersey: Wiley, 2012.

PORTAL LEI GERAL DA MICRO E PEQUENA EMPRESA (Org.). 0 que é a lei geral? Portal Lei Geral, 2015. Disponível em: <http://www.leigeral.com.br/o-site/o-que-e-a-leigeral>. Acesso em: 19 de nov. de 2017.

RAMOS, M. P.; SCHABBACH, L. M. O estado da arte da avaliação de políticas públicas: conceituação e exemplos de avaliação no Brasil. Revista de Administração Pública RAP, v. 46, n. 5, p. 1271-1294, 2012.

RFB (Org.). Tabela de Natureza Jurídica e Qualificação do Representante da Entidade publicado em 2016. Disponível em:

<https://www.receita.fazenda.gov.br/pessoajuridica/cnpj/tabelas/natjurqualificaresponsavel.ht m>. Acessado em: 20 de set. de 2018.

RFB (Org.). Sistema Normas Gestão da Informação. Resolução CGSN no 140 de 22 de maio de 2018. Dispõe sobre o Regime Especial Unificado de Arrecadação de Tributos e Contribuições devidos pelas Microempresas e Empresas de Pequeno Porte (Simples Nacional). Diário Oficial da União, Brasília, publicado em 24 de maio de 2018. 
SEBRAE (Org.). Os negócios promissores em 2017 - publicado em dezembro de 2016. Disponível em:

$<$ https://www.sebraemg.com.br/atendimento/bibliotecadigital/documento/Diagnostico/Osnegocios-promissores-em-2017>. Acessado em: 26 de ago. de 2018.

SEBRAE (Org.). Anuário do trabalho nos pequenos negócios: 2015. 8aㅡ ed. Serviço Brasileiro de Apoio às Micro e Pequenas Empresas; Departamento Intersindical de Estatística e Estudos Socioeconômicos [responsável pela elaboração da pesquisa, dos textos, tabelas, gráficos e mapas]. Brasília, Distrito Federal: DIEESE, 2017a.

SEBRAE (Org.). Relatório especial: os impactos do Simples Nacional - publicado em julho de 2017b. Disponível em:

$<$ https://bibliotecas.sebrae.com.br/chronus/ARQUIVOS CHRONUS/bds/bds.nsf/1513cca8cf 40729aa779c2d6d1885252/\$File/7733.pdf>. Acessado em: 26 de ago. de 2018.

SENADO FEDERAL (Org.). Relatório de avaliação da política pública do Simples Nacional - regime especial unificado de arrecadação de tributos e contribuições devidos pelas microempresas e empresas de pequeno porte - em atendimento ao que dispõe a resolução do Senado Federal no 44, de 2013 e ao requerimento no 16/2017 publicado em novembro de 2017.

SOUZA, C. Políticas Públicas: uma revisão da literatura. Revista Sociologias, v. 1, n. 16, p. 20-45, 2006.

TAVARES, D. Lei Geral das Micro e Pequenas Empresas já está em vigor. Revista SEBRAE, v. 1, n. 20, p. 20-39, 2007.

WU, X.; RAMESH, M.; HOWLETT, M.; FRITZEN, S. Guia de políticas públicas:

gerenciando processos. Traduzido por: Ricardo Avelar de Souza. Brasília: ENAP, 2014.

\section{LISTA DE ANEXOS}

Anexo I - Teste de Hausman (modelo I).

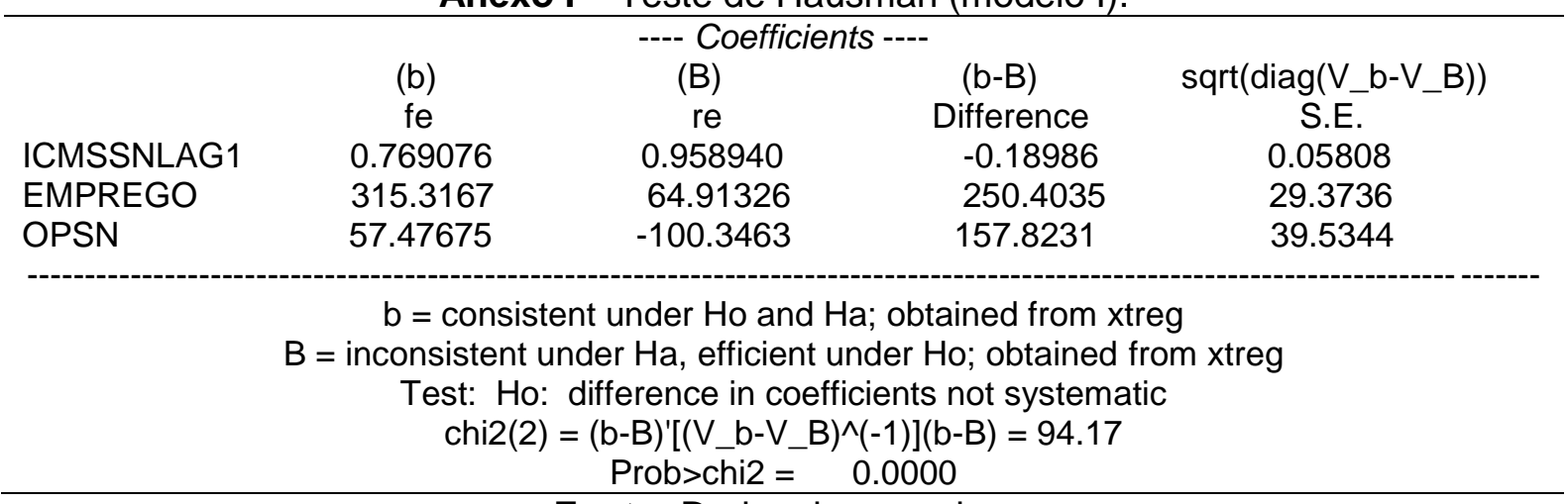

Fonte: Dados da pesquisa.

Anexo II - Teste de Hausman (modelo II).

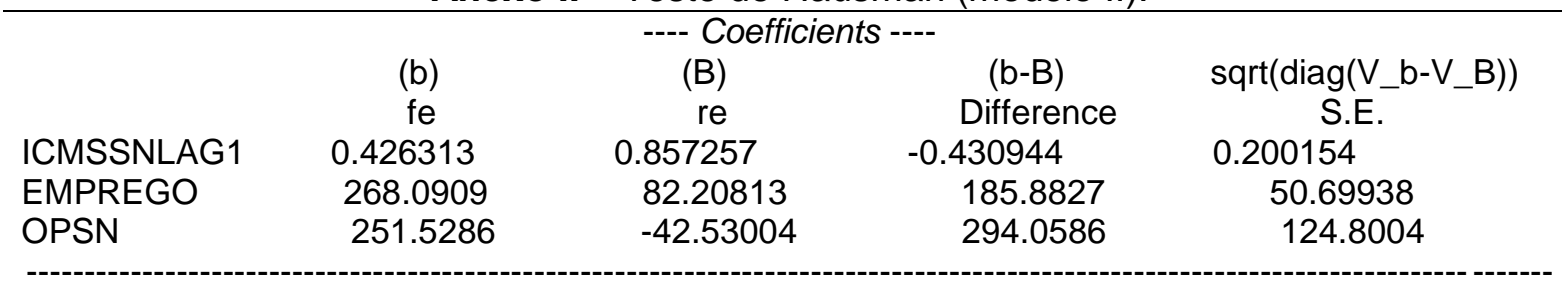

$\mathrm{b}=$ consistent under $\mathrm{Ho}$ and $\mathrm{Ha}$; obtained from xtreg

$\mathrm{B}=$ inconsistent under $\mathrm{Ha}$, efficient under $\mathrm{Ho}$; obtained from xtreg 
Test: Ho: difference in coefficients not systematic

$\operatorname{chi} 2(3)=(b-B)^{\prime}\left[\left(V \_b-V \_B\right)^{\wedge}(-1)\right](b-B)=22.11$

Prob $>$ chi2 $=0.0001$

Fonte: Dados da pesquisa.

\section{NOTAS DE AUTOR}

\section{CONTRIBUIÇÃO DE AUTORIA}

Daniel Rodrigues Cordeiro - Concepção e elaboração do manuscrito. Análise de dados. Elaboração do manuscrito, revisão e aprovação da versão final do trabalho.

Everlam Elias Montibeler - Concepção e elaboração do manuscrito. Elaboração da metodologia. Elaboração do manuscrito, revisão e aprovação da versão final do trabalho.

Daniel Ribeiro de Oliveira - Coleta de dados. Participação ativa da discussão dos resultados. Revisão e aprovação da versão final do trabalho.

\section{FINANCIAMENTO}

Bolsa de mestrado do autor Daniel Rodrigues Cordeiro. Órgão financiador: FAPERJ - Fundação Carlos Chagas Filho de Amparo à Pesquisa do Estado do Rio de Janeiro. Processo: E-26/201.055/2017.

\section{CONSENTIMENTO DE USO DE IMAGEM}

Não se aplica.

\section{APROVAÇÃO DE COMITÊ DE ÉTICA EM PESQUISA}

Não se aplica.

\section{CONFLITO DE INTERESSES}

Não se aplica.

\section{LICENÇA DE USO}

Este artigo está licenciado sob a Licença Creative Commons CC-BY. Com essa licença você pode compartilhar, adaptar, criar para qualquer fim, desde que atribua a autoria da obra.

\section{HISTÓRICO}

Recebido em: 27-06-2019

Aprovado em: 20-05-2020 